\title{
Effects of sintering temperature on the densification of WC-6Co cemented carbides sintered by coupled multi-physical-fields activated technology
}

\author{
Yu Zhou ${ }^{1}$, Yi Yang ${ }^{1, *}$, Gang Yang ${ }^{1}$, Deqiang Yin ${ }^{1}$, Yi Qin ${ }^{2}$, and Jian Liu ${ }^{1, *}$ \\ 1 School of Manufacturing Science and Engineering, Sichuan University, 610065 Chengdu, China \\ 2 Department of Design, Manufacture \& Engineering Management, University of Strathclyd, G1 1XQ Glasgow, UK
}

Received 6 January 2015 / Accepted 25 June 2015

\begin{abstract}
Sample parts with WC-6Co cemented carbides were manufactured successfully with a novel method called coupled multi-physical-fields (electric field, temperature field and force field) activated sintering technology, using a Gleeble-1500D thermal simulation machine. Effects of sintering temperature on the densification, microstructures and hardness of samples were investigated. It was found that densification of the samples was enhanced with the increase of the sintering temperature and a relative density of as high as $98.76 \%$ achieved when a sintering temperature of $1200{ }^{\circ} \mathrm{C}$ was used. The particle size of the WC in sintered samples increased from $1.837 \mu \mathrm{m}$ to $2.897 \mu \mathrm{m}$ when the temperature was increased from $1000{ }^{\circ} \mathrm{C}$ to $1200{ }^{\circ} \mathrm{C}$, resulting in the decrease of the hardness from HRC 63.5 to HRC 61.7. The presented work shows that, potentially, coupled multi-physical-fields activated technology is able to produce hard alloys to meet the engineering applications.
\end{abstract}

Key words: WC-6Co, Sintering temperature, Densification, Multi-physical-fields activated sintering

\section{Introduction}

Cemented carbides are widely used in a variety of applications such as machining, cutting and drilling, owing to their high hardness, excellent wear resistance and toughness [1-3]. Generally, cemented carbides consist of a high volume fraction of the "hard" hexagonal WC phase embedded within a soft and tough binder phases, such as $\mathrm{Co}, \mathrm{Ni}$ and Fe and they are usually manufactured with conventional powder metallurgy (PM) techniques.

Conventional powder metallurgy involves mixing the metal powders, compacting of the mixed powders into molds and then sintering of the compact powders under different atmospheres. Chang and Chen [4] successfully fabricated WC-Co cemented carbides at the sintering temperature of $1350{ }^{\circ} \mathrm{C}$ using a vacuum sintering method and their results showed that hardness of HRA 84.4 was obtained when the relative density of the sample reached $99.76 \%$. Zhao et al. [5] studied effects of the sintering temperature on the mechanical properties of WC-Fe-Cu hard alloys and found that relative densities of the hard alloys increased with the increasing sintering temperature. When a traditional sintering method is used to

*e-mail: yiyang_scu@163.com; Iiujian@scu.edu.cn fabricate the cemented carbides, a high temperature is usually required to produce a liquid phase from the binders and promote the densification process. However, formation of the liquid phase will inevitably lead to the growth of WC particles due to Ostwald ripening [6], and seriously degrade mechanical properties of the cemented carbides.

So far, a variety of methods have been attempted in order to control the WC particle size while achieving sufficient densification of the cemented carbides. A typical method among them is to introduce some inhibiters such as $\mathrm{VC}, \mathrm{Cr}_{3} \mathrm{C}_{2}, \mathrm{NbC}$ and $\mathrm{TaC}$, into the matrix materials. In particular, $\mathrm{VC}$ and $\mathrm{Cr}_{3} \mathrm{C}_{2}$ are the most effective particle growth inhibitors due to their high solubility and mobility in the cobalt phase at lower temperatures [7]. Furushima et al. [8] and Espinosa-Fernández et al. [9] investigated the effects of $\mathrm{VC}$ and $\mathrm{Cr}_{3} \mathrm{C}_{2}$ on the mechanical properties of the WC-FeAl and WC-Co alloy materials respectively and found that the additions of $\mathrm{VC}$ or $\mathrm{Cr}_{3} \mathrm{C}_{2}$ could suppress the growth of the WC particles and refine the microstructures of materials, resulting in the improved Vickers hardness. However, degraded transverse rupture strength was noticed due to the introduction of the $\mathrm{VC}$ or $\mathrm{Cr}_{3} \mathrm{C}_{2}$ particles.

Another alternative method for producing cemented carbides with fine microstructures is to directly sinter the nano-sized starting materials. Jia et al. [10] used WC powders 
with the particle size of $80 \mathrm{~nm}$ and Co powders with a particle size of $60 \mathrm{~nm}$ to fabricate the WC-Co cemented carbides, and a series of processing parameters were attempted to find the optimum ones where excellent mechanical properties could be achieved. The results showed that although hardness of as high as HRA 92 could be obtained, WC particle grew up rapidly with the increasing sintering temperature, seriously limiting the improvement in the mechanical properties of the materials.

Recently, a plethora of fast sintering techniques including spark plasma sintering (SPS) [11, 12], microwave sintering [13] and high frequency induction-heated sintering (HFIHS) [14-16] have been developed or optimized and particle growth can be efficiently suppressed by using these techniques since sintering processes can be achieved in a much shorter time and at a relatively lower temperature than those by using a traditional approach. Bao et al. [17] fabricated WC-8Co cemented carbides of nearly full densification by microwave irradiation and suggested that the WC grain size and distribution are determined mainly by the sintering temperature in the microwave sintering. Lidong and Hailiang [18] discussed the relationship between the sintering temperature and properties of nano-sized cemented carbides prepared by SPS and found that substantial growth of WC particles took place at high temperatures.

More recently, a sintering method named as coupled multiphysical-fields activated sintering technology [19] was put forward for the sintering of WC-6Co cemented carbides. The "coupled multi-physical-fields", in this case, means that mechanical force, temperature field and electrical field are acting and superimposed simultaneously, for promoting the material's densification process. The method has merits such as low sintering temperature, short forming time, and remarkable inhibition of particle growth without addition of inhibitors. Using this novel method, Huang et al. [20] successfully fabricated WC-6Co cemented carbides with a density of $97 \%$ achieved at a sintering temperature of $850{ }^{\circ} \mathrm{C}$. However, in their work, effects of the processing parameters on the microstructures and mechanical properties were not explored. As numerous reports indicated, the final, WC particle size strongly depends on the sintering temperature to be used and mechanical properties of the cemented carbides are largely dependent on the particle size of the WC formed. Therefore, in this study, we aimed at fabricating WC-6Co cemented carbides using coupled multi-physical-fields activated technology and investigating effects of sintering temperature on the densification, microstructures and mechanical properties of the samples.

\section{Material and experiment}

For the raw material, WC and Co powders both with an average particle size (APS) of $0.6 \mu \mathrm{m}$ and a purity of $99 \%$ were used for the experiments. WC and Co powders were ball milled in a GN-2 high energy machine for $4 \mathrm{~h}$ at a milling speed of $400 \mathrm{rpm}$ to produce powder mixtures with composition of 94 wt.\% WC- 6 wt.\% Co. A ball to powder ratio of $6: 1$ was used for the ball milling process. Afterwards, the mixed powders were loaded into a small die with inner diameter of $4 \mathrm{~mm}$, outer diameter of $20 \mathrm{~mm}$ and height of $4 \mathrm{~mm}$.

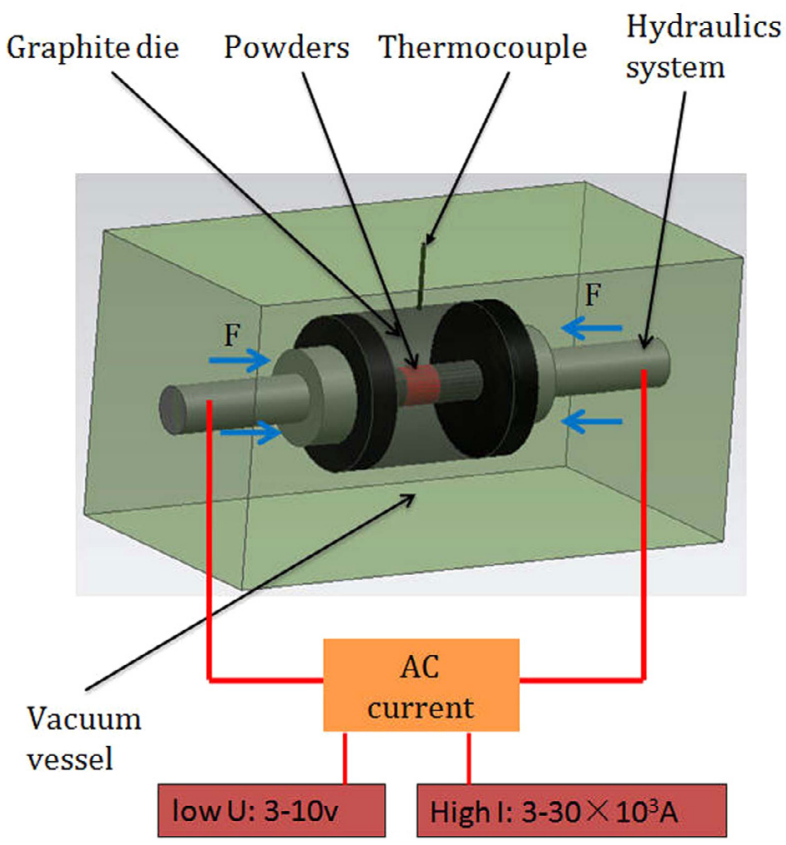

Figure 1. Schematic diagram of Gleeble-1500D machine.

The experiments were carried out using a Gleeble-1500D thermal simulation machine (Dynamic System Inc, USA). The schematic map of the machine is shown in Figure 1. The die was installed between the two electrodes of the Gleeble-1500D machine and thermocouple wires were soldered onto the surface of the die to measure the sintering temperature. The required experimental heating conditions were pre-programmed into the computer control system. Sintering temperatures of $1000{ }^{\circ} \mathrm{C}, 1100{ }^{\circ} \mathrm{C}$ and $1200{ }^{\circ} \mathrm{C}$ were adopted in the experiments. The chamber was first evacuated to less than $10^{-3} \mathrm{~Pa}$ before the sintering process started. Afterwards, WC-6Co powders were rapidly heated to sintering temperature at the preset heating rate of $50{ }^{\circ} \mathrm{C} / \mathrm{s}$. Simultaneously, a pressure of $50 \mathrm{Mpa}$ was applied to the powders through the punches when the heating process was started for each setting. More detailed processing parameters can be found in Table 1 . After a 4 min thermal soaking time, the Gleeble-1500D thermal simulation machine was turned off and the sample was cooled down to room temperature. It is worthy mentioning that the total forming process only takes less than $5 \mathrm{~min}$.

The relative densities of the samples were measured by the Archimedes' principle. Sintered samples were polished and etched using Murakami's reagent (10 g potassium ferricyanide, $10 \mathrm{~g}$ sodium hydroxide and $100 \mathrm{~mL}$ water) for $60 \mathrm{~s}$ at room temperature and microstructures were examined using SEM (Hitachi S-4800). Phase compositions of the sintered samples were determined by XRD (DX-2500 X). Rockwell hardness measurements were made on the polished surfaces of the samples and all the reported data were the average of at least five test results. The average particle size (APS) of the crosssection was measured using an analytical software and more than a hundred WC grains were measured from the micrographs of the corresponding sintered sample. The APS was calculated based on the intercept method. 
Table 1. Processing parameters.

\begin{tabular}{llcccc}
\hline Sample & Material & Sintering temperature $\left({ }^{\circ} \mathrm{C}\right)$ & Soaking time $(\mathrm{min})$ & Pressure $(\mathrm{MPa})$ & Heating rate $\left({ }^{\circ} \mathrm{C} / \mathrm{s}\right)$ \\
\hline $1 \#$ & WC-6Co & 1000 & 4 & 50 & 50 \\
$2 \#$ & WC-6Co & 1100 & 4 & 50 & 50 \\
$3 \#$ & WC-6Co & 1200 & 4 & 50 & 50 \\
\hline
\end{tabular}

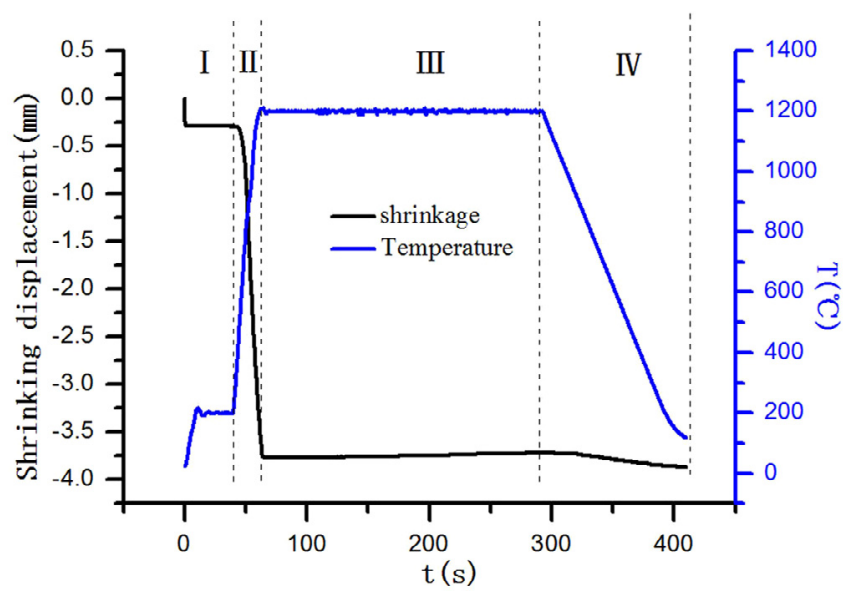

Figure 2. Variations of temperature and shrinkage displacement with the time during the processing of WC-6Co hard alloys (under the pressure of $50 \mathrm{MPa}$, the sintering temperature of $1100{ }^{\circ} \mathrm{C}$ ) (I) pre-heating period, (II) heating period, (III) soaking period, (IV) cooling period.

\section{Results and discussions}

\subsection{Densification behavior}

The shrinkage displacements and temperatures on the surface of the graphite die during the sintering process are shown in Figure 2. It can be seen that the whole sintering can be divided into four periods: (I) pre-heating period, (II) heating period, (III) soaking period, (IV) cooling period. In particular, dramatic shrinkage is observed in the heating period, which implies the densification process is considerably enhanced and densification is completed mainly in this period.

From the Figure 2, it can be seen that there is no noticeable shrinkage in the pre-heating period. In this period, powders were compressed under the action of the pressure and then heated to $200{ }^{\circ} \mathrm{C}$ and soaked for $30 \mathrm{~s}$ to drive out the gas among the powders. As a result, the electrical conductivity of the sample is improved and the current passing through the samples is facilitated.

In the heating period, the sample was heated rapidly to the sintering temperature by the joule heat generated by the current passing the sample. It is expected that both plastic and elastic deformation occurred in the powder particles under the effects of both pressure and the joule heat, leading to the increased contact area among particles. At the same time, the small particles can be squeezed into the space among big particles, increasing the density of the sample and accelerating the current to pass the samples. It should be noted that local liquid phase is likely to be formed under the effects of electric, temperature and force fields

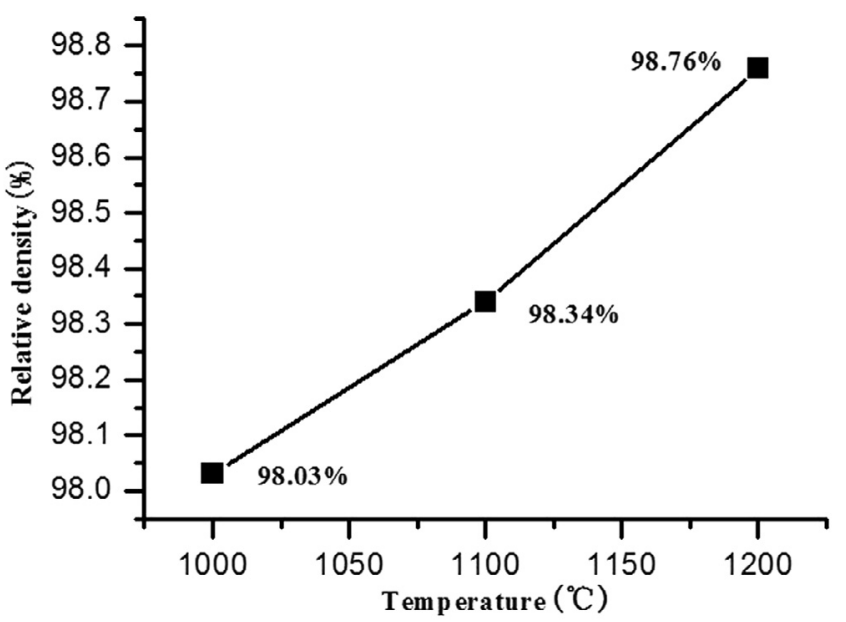

Figure 3. Relative densities of the cemented carbides sintered at different sintering temperatures ranging from $1000{ }^{\circ} \mathrm{C}$ to $1200{ }^{\circ} \mathrm{C}$.

during this period. Due to the capillary force, the densification process will be significantly enhanced. Consequently, the considerable shrinkage is noticed in this period.

In the soaking period, the sample was soaked at the sintering temperature below than the melting point of the cobalt and the eutectic point between WC and Co [21]. However, the local temperature between the particles may be higher than the melting point of the cobalt and the eutectic point between $\mathrm{WC}$ and Co because of the electrothermic focus effect during the sintering process [22]. Therefore, it is highly likely that a large portion liquid phase will be formed. Once the liquid is formed, it tends to spread over the WC particles to reduce the surface energy and increase the density of the sample. In addition, the liquid phase can promote solid diffusion of the system due to the improved interconnection between reactant particles. As a result, the relative density and hardness of samples increase with the heating process. It is worthy noting that the soaking time should not be too long, lest secondary recrystallization takes place [23] and reduce the density of the sample.

In the cooling period, the sample was cooled down to the room temperature in a slow manner so as to avoid the formation of cracks.

\subsection{Effect of sintering temperature on the densification of WC-6Co cemented carbides}

The relative densities of WC-6Co specimens sintered at different temperatures are shown in Figure 3. It can be seen that high relative densities are achieved for all the WC-6Co specimens sintered under coupled multi-physical fields. 

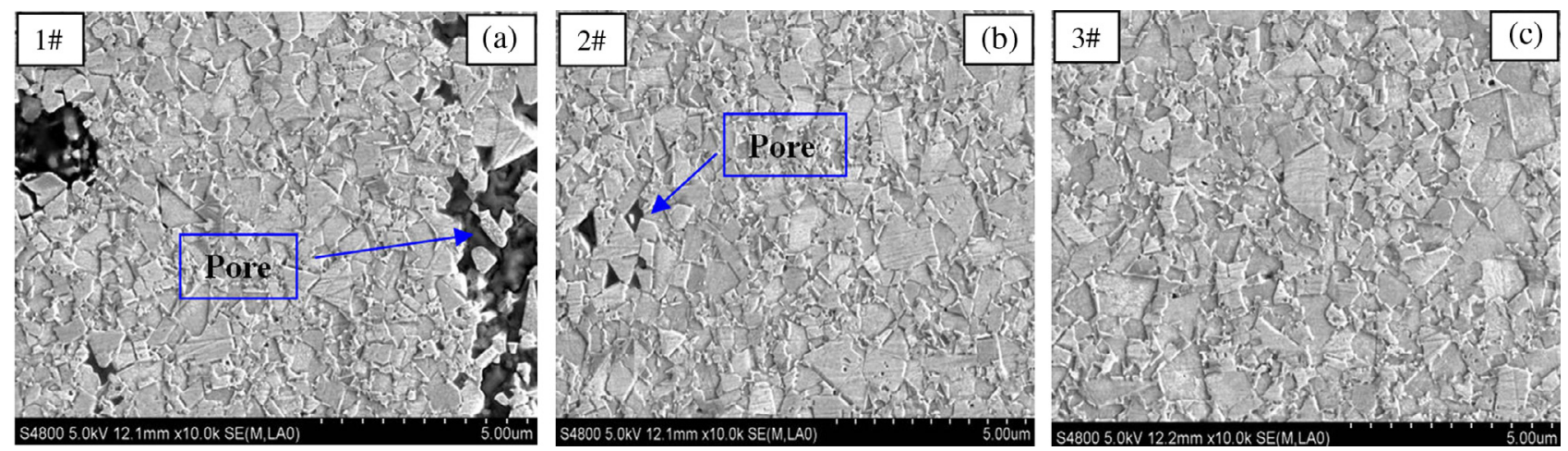

Figure 4. SEM images of WC-6Co cemented carbides sintered at different temperature (a) $1000{ }^{\circ} \mathrm{C}$, (b) $1100{ }^{\circ} \mathrm{C}$, (c) $1200{ }^{\circ} \mathrm{C}$.
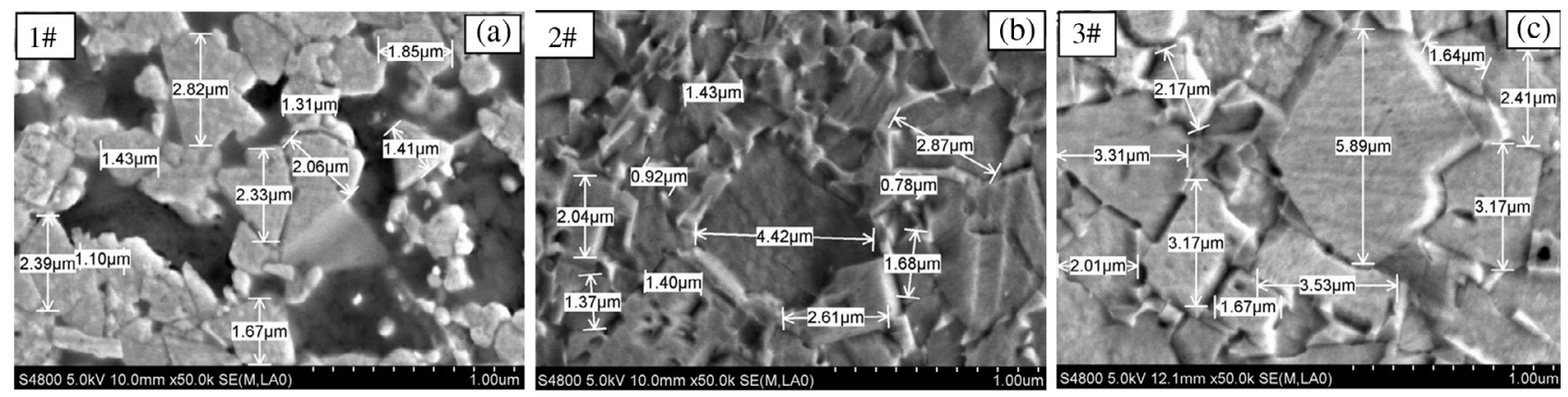

Figure 5. The SEM images of WC-6Co cemented carbide samples sintered at different sintering temperatures, showing the WC particle sizes in the samples (a) $1000{ }^{\circ} \mathrm{C}$, (b) $1100{ }^{\circ} \mathrm{C}$, (c) $1200{ }^{\circ} \mathrm{C}$.

In addition, relative densities of the sintered specimens increase with the increasing temperature.

Figure 4 shows microstructures of WC-6Co cemented carbides sintered at different sintering temperatures. It can be seen that noticeable pores are present in the samples sintered at $1000{ }^{\circ} \mathrm{C}$ and $1100{ }^{\circ} \mathrm{C}$ respectively while the sample sintered at $1200{ }^{\circ} \mathrm{C}$ exhibit a more dense microstructure, implying that the densities of the $1 \#$ and $2 \#$ samples are both lower than the density of the $3 \#$ sample and the density of the sample increases with the increasing sintering temperature. In particular, when sintering temperature of $1200{ }^{\circ} \mathrm{C}$ is reached, the highest relative density of $98.76 \%$ is achieved.

\subsection{Effect of sintering temperature on the WC particle sizes formed}

Figure 5 shows the SEM images of WC-6Co cemented carbides sintered at different sintering temperatures. It can be seen that the sintering temperature has appreciable effects on the particle size, and the particle size of samples sintered by couple multi-physical fields activated technology is small and uniform. The average particle sizes of samples sintered at temperatures of $1000{ }^{\circ} \mathrm{C}, 1100{ }^{\circ} \mathrm{C}$ and $1200{ }^{\circ} \mathrm{C}$ are $1.837 \mu \mathrm{m}$, $1.952 \mu \mathrm{m}$ and $2.897 \mu \mathrm{m}$ respectively, which implies that the average particle sizes of samples increase as the sintering temperature increases.
Although a relatively low sintering temperature was used in the coupled multi-fields sintering of WC-Co cemented carbides, a high temperature in some local areas of the samples can be still be achieved due to the increased contact resistance between powder particles. As a result, liquid phases either from the eutectic reaction between WC and Co or from melting Co are likely to be formed during the sintering process. Once the liquid phases are formed, they will instantly spread over the WC particle and fill in the pores within the samples because of the capillary force, enhancing the densification process. On the other hand, small WC particles can dissolve into the liquid phase in the heating process and the dissolved $\mathrm{W}$ and $\mathrm{C}$ will later precipitate on the surfaces of the large WC particles, leading to the occurrence growth of WC particles. In addition, when a higher sintering temperature is employed during the sintering process, more liquid phase tends to be formed, resulting in faster growth of the WC particles.

\subsection{Effect of sintering temperature on mechanical properties}

Figure 6 shows the hardness of WC-6Co cemented carbides sintered at different sintering temperatures. It can be observed that the hardness decreases with the increasing sintering temperature. The variation of the hardness can be explained by the effects of both the porosity and WC particle size in the sintered samples. Usually the higher porosity leads to the lower 


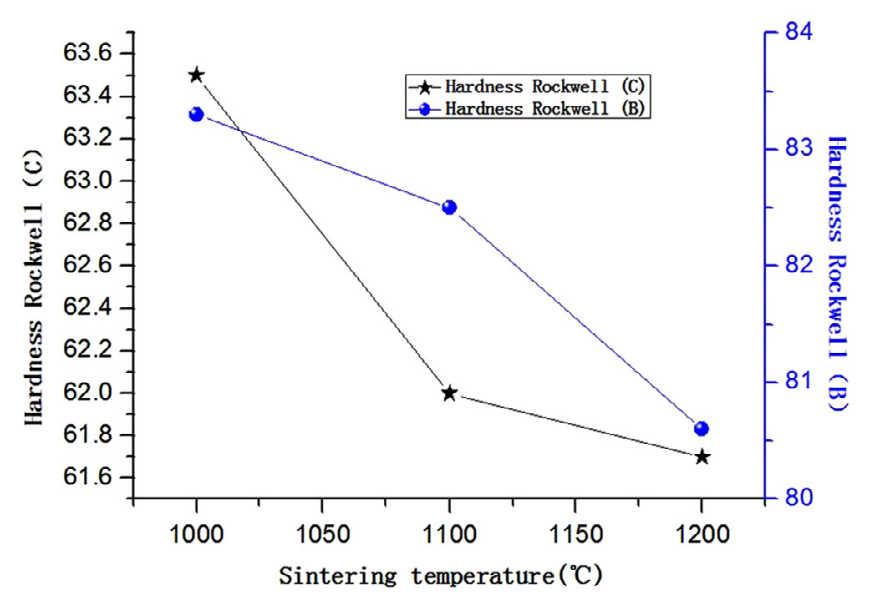

Figure 6. Hardness of WC-6Co cemented carbides sintered at different sintering temperatures.

hardness. As the Hall-Petch equation indicates the larger the particle size, the lower the hardness. Although the sample sintered at $1200{ }^{\circ} \mathrm{C}$ has the lowest porosity suggested by Figure 5, the smallest hardness is obtained due to the formation of the largest WC particle size at the temperature. Therefore, it is expected that raising the sintering temperature can promote the particle growth of $\mathrm{WC}$, causing the decrease of hardness.

\section{Conclusions}

Sintering of WC-6Co cemented carbides with fine microstructures has been achieved using coupled multiphysical-fields sintering technology, at relatively low sintering temperatures, and with a short cycle time. Particularly, WC-6Co cemented carbides with a relative density of $98.76 \%$ have been obtained at a sintering temperature of $1200{ }^{\circ} \mathrm{C}$. The research also shows that the sintering temperature has determinate effects on the densification, microstructure and hardness formation of the parts formed. Relative density of the samples formed increases with increase of the sintering temperature. Nevertheless, hardness of the samples decreases with increase of the sintering temperature. The decrease of the hardness can be explained as due to the faster growth of WC particles at higher sintering temperatures. The presented work suggests that coupled multi-physical-fields sintering is an efficient method for sintering WC-6Co cemented carbides. Through further development, including process optimization, the method is expected to be used for forming engineering components either for achieving much better performance or to meet more challenging applications, comparing to that currently with WC-6Co cemented carbides.

Acknowledgements. The authors would like to acknowledge the support from the National Nature Science Foundation of China (No. 51275322) and the UK Royal Society/China NSFC International
Exchanges Programme on the collaborative development of a new micro-manufacturing process.

\section{References}

1. S.I. Cha, S.H. Hong, B.K. Kim, Materials Science and Engineering: A 351 (2003) 31-38.

2. V. Bounhoure, S. Lay, S. Coindeau, et al., International Journal of Refractory Metals and Hard Materials 52 (2015) 21-28.

3. W. Su, Y. Sun, J. Feng, et al., International Journal of Refractory Metals and Hard Materials 48 (2015) 369-375.

4. S.H. Chang, S.L. Chen, Journal of Alloys and Compounds 585 (2014) 407-413.

5. Z. Zhao, J. Liu, H. Tang, et al., Journal of Alloys and Compounds 632 (2015) 729-734.

6. X. Sun, Y. Wang, D.Y. Li, Wear 301 (2013) 406-414.

7. C.W. Morton, D.J. Wills, K. Stjernberg, International Journal of Refractory Metals and Hard Materials 23 (2005) 287-293.

8. R. Furushima, et al., International Journal of Refractory Metals and Hard Materials 50 (2015) 16-22.

9. L. Espinosa-Fernández, A. Borrell, M.D. Salvador, et al., Wear 307 (2013) 60-67.

10. C. Jia, L. Sun, H. Tang, et al., International Journal of Refractory Metals and Hard Materials 25 (2007) 53-56.

11. X. Ren, Z. Peng, C. Wang, et al., International Journal of Refractory Metals and Hard Materials 48 (2015) 398-407.

12. M. Eriksson, M. Radwan, Z. Shen, International Journal of Refractory Metals and Hard Materials 36 (2013) 31-37.

13. R. Bao, J. Yi, H. Zhang, International Journal of Refractory Metals and Hard Materials 32 (2012) 16-20.

14. H.C. Kim, I.K. Jeong, I.J. Shon, International Journal of Refractory Metals and Hard Materials 25 (2007) 336-340.

15. H.C. Kim, I.J. Shon, J.K. Yoon, et al., International Journal of Refractory Metals and Hard Materials 24 (2006) 202-209.

16. I.J. Shon, I.K. Jeong, I.Y. Ko, Ceramics International 35 (2009) 339-344.

17. R. Bao, J. Yi, Y. Peng, Transactions of Nonferrous Metals Society of China 23 (2013) 372-376.

18. X.Y.W.X.C. Lidong, L.I.X.G. Hailiang, Cemented Carbide 3 (2003) 004.

19. Y. Yang, K.L. Huang, G. Yang, D.Q. Yin, Y. Zhou, Y. Qin, Micromanufacturing Engineering and Technology, edited by Y. Qin, 2nd edn. (Elsevier, UK, 2015).

20. K.L. Huang, Y. Yang, Y. Qin, Y. Yang, D.Q. Yin, in Proceedings of the 11th International Conference on Manufacturing Research, 2013, edited by Essam Shehab, Peter Ball, Benny Tjahjono (Cranfield University Press, Cranfield University, 2013), p. 369.

21. T. Yamamoto, Y. Ikuhara, T. Sakuma, Science and Technology of Advanced Materials 1 (2000) 97-104.

22. M.X. Wu, G. Yang, Y. Yang, D.Q. Yin, Y. Zhou, Journal of Sichuan University: Engineering Science Edition 46 (2014) 171-175.

23. Y.C. Zhu, C.X. Ding, K. Yukimura, et al., Ceramics International 27 (2001) 669-674. 